BAPTISTA L.O. Contratos internacionais. Revista Forense, año 76 , vol. 270, fasciculos 922,923 y 924 , abrilmayo-junio de 1980 , p. 87-100.

BOGGIANO A: Derecho Internacional Privado. Tomo Buenos Aires, Depalma, 1983, 2.ed. 692p.

CÂMARA DE COMÉRCIO INTERNACIONAL. Incoterms 1990. Publicación $n^{0} 460$ de la Câmara de Comércio Internacional. São Paulo, Aduanerias, 1991. Traducción: Roberto de Oliveira Murta. Publicación autorizada por la ICC Publishing S.A.

CARREAU D., FLORY T., JUILLARD P. Droit International Economique. 3a ed. Paris, Librarie Générale de Droit et de Jurisprudence, 1990,725 .

GOLDSCHMIDT W. Derecho Internacional Privado - De recho de la tolerancia. Buenos Aires, Depalma, 1985. 5 a ed. 760p.

GRAF J.B. Legal trend of international sales in Latin America. In: John Honnold, Unification of the Law of Go verning International Sales of Goods.

ACHADO M.L. Os incoterms. In: Contratos Internacionais. Coordinador Joaao Grandino Rodas. Sao Pau-

MALAURIE P. Lois de Police et méthodes de conflits de

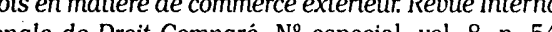

550. Journées de la société de législation comparée. Año 1986. 10es Journées franco-latino-américaines (Bogotá, 30 de noviembre -3 de diciembre). RODAS J.G. Elementos de conexáo do Direito Internacional Privado brasileiro relativamente às obrigaçöes contratuais. In: Contratos internacionais, coordinador J. Grandino Rodas. Saao Paulo, REvista dos Tribunais, 1985. p. 1-36.

ROVIRA S.L.Z. de. Estudo comparativo sobre os contratos internacionais: aspectos doutinarios $e$ práticos. In: Contratos Internacionais, coordinador J. Grandino Rodas. p. 37-75.

SIERRALTA RIOS A. Contratos de comercio internacional. Prólogo de Carlos Rodriguez Pastor. Lima, fondo Editorial de la Pontificia Universidad Católica del Perú, 1990. XVIII, 224p.

LVA C.V. do C. e. A obrigação como processo. São Paulo, José Bushtsky, 1976, 226p.

EIRA, M.A. Aproximación de las legislaciones, aspectos doctrinarios. In: Doctrina general - Cuadernos de Derecho Internacional Privado. № 2. p. 121-157. Mo aRBINL E.C. de J A Convencáo de Viena de 1980 sobre

a venda internacional de mercadorias. In: Contratos internacionais. p. 76-93.

\title{
Breves Considerações Sobre a Substituição Tributária. A Tributação na Fonte*
}

\section{CARLOS KLEIN ZANINI}

Graduado em Ciências Jurídicas pela Faculdade de Direito da UFRGS. Mestrando em Direito Comercial

pela Faculdade de Direito da Universidade de São Paulo.

Membro do Instituto Brasileiro de Direito Comercial Comparado - S.P. Professor de Direito Comercial na UNISINOS.

Professor da Faculdade de Direito da PUC/RS Advogado em Porto Alegre, RS

\section{INTRODUÇÃO}

0 presente trabalho aborda o tema da substituição tributária, enfocando, especificamente, a tècnica da tributação na fonte. Importante ressaltar, desde já, a complexidade da matéria, que se reflete na diversidade de opiniōes existentes em doutrina, e que, sem dúvida alguma, torna árdua a tarefa daqueles que se propõem a versá-la.

Dessarte, cientes da polêmica reinante entre os autores, partiremos da análise das diversas teorias existentes, para esboçar, ao fim de cada item, nossa posição pessoal.

A importância do tema é inconteste. Como veremos ao longo da exposição o emprego da tributação na fonte tem se propagado com incrive rapidez, sendo, portanto, interessante e necessária a reflexão sobre as dificuldades que podem advir de sua utilização.

0 presente estudo vai, pois, seccionado em dois pontos. No primeiro deles - de caráter in trodutório - examinaremos a classificação do sujeitos passivos, o enquadramento do substituto na obrigação tributária, além do seu conceito e dos traços que o distinguem do contribuinte.

A seguir, passaremos à análise da tributação na fonte, expondo suas vantagens e desvanta-

-Trabalho desenvolvido no curso de pós-graduacão da Faculdade de Direito da US P. disciplina de Impostos Federais, ministrada pelos Professores Doutores Alcides Jorge Costa e Gerd Willi Rothmann.

gens, sua conexão estreita com o principio da legalidade e sua natureza jurídica. Assentadas tais noções preliminares, adentraremos no exame do direito de regresso, procurando responder a duas interessantes indagações que têm lugar quando do recolhimento pelo substituto de tributo indevido.

Por último, discorreremos sobre a responsado sustituido quando do não recolhimento do tributo pelo substituto, apontando qual a solução que deve ser aplicada a tal situação.

\section{OS SUJEITOS PASSIVOS TRIBUTÁRIOS}

\subsection{A Classificação dos Sujeitos Passivos}

Para que possamos avançar no propósito deste trabalho, faz-se necessário, ab initio, examinar brevemente, as diversas posicões doutrinárias existentes a respeito da sujeição passiva tributária. Muitos são os autores que versaram o tema ${ }^{1}$, porém, a copiosa bibliografia disponivel, ao invés de estancar dúvidas, as suscita, porquanto reine entre os doutrinadores séria divergência de opiniōes.

Dentre tais questões deve ser enfrentada de inicio a referente à classificação dos sujeitos passivos. Para tanto, utilizaremos a sistematização elaborada por Héctor Villegas em seu 
Curso de Direito Tributário. ${ }^{2} 0$ jurista argentino agrupa as diferentes teses em quatro correntes principais $^{3}$, que analisaremos separadamente: 1) primeira corrente - divide os sujeitos passivos em contribuintes (sujeitos por divida própria) e responsáveis (sujeitos por divida alheia) 2) segunda corrente - somente considera sujeito passivo o contribuinte ou devedor, negando caráter de sujeito passivo aos demais; 3 ) terceira corrente - seriam sujeitos passivos somente 0 contribuinte e o substituto, excluindo-se responsável; 4) quarta corrente - sujeito passivo é quem concretamente paga o tributo ao fisco.

2.1.1. Primeira Corrente. Classificação de Rubens Gomes de Sousa

A primeira corrente referida por Villegas daqueles que consideram como sujeitos pass vos tanto os contribuintes quanto os responsa veis - tem seu maior corifeu, dentre os autores pátrios ${ }^{4}$, em Rubens Gomes de Sousa, que classifica as pessoas compelidas a cumprir a prestação objeto da obrigação tributária em sujeito passivos diretos e indiretos, consoante estejam ou não "em relação econômica com 0 ato, fato ou negócio que dá origem à tributação"5. Na hipótese de sujeição passiva indireta, 0 autor subdivide em transferência e substituição: transferência quando a obrigação tributária nasce contra determinada pessoa e, posteriormente, transferida à outrem (sujeito passivo indireto); substituição quando a obrigação tributária surge já contra pessoa diversa (sujeito passivo indireto) daquela vinculada economicamente ao ato fato ou negócio tributado ${ }^{6}$.

\subsubsection{A Terminologia Adotada Pelo C.T.N.}

O artigo 121 do Código Tributário Nacional por sua vez, englobou todas as hipóteses de sujeição passiva indireta sob a figura do responsável. Tal o que se entende da leitura desse dispositivo assim vazado: "art. 121 - Sujeito passivo da obrigação principal é a pessoa obrigada ao pagamento de tributo ou penalidade pecun ária. Parágrafo Único. $O$ sujeito passivo da obrgação principal diz-se: I - contribuinte, quando tenha relação pessoal e direta com a situa- ção que constitua o respectivo fato gerador; II responsável quando, sem revestir a condição de contribuinte, sua obrigação decorra de disposição expressa de lei". O Código filia-se, portanto como não poderia deixar de ser, à corrente defendida por Rubens Gomes de Sousa, que considera o substituto como sujeito passivo integrante da obrigação tributária.

\subsubsection{Segunda Corrente Doutrinária}

\section{Negadora do Substituto Como Sujeito}

Passivo. A Posição de Giannini

Existem, contudo, outros autores que negam o caráter de sujeito passivo da obrigação tributária ao substituto. Para os defensores desta corrente somente seriam considerados como sujeitos passivos os contribuintes ou devedores. Essa a posição que ressai da leitura atenta de trecho da obra de A.D. Giannini, que ao abordar a substituição e responsabilidade tributárias, assim manifesta-se, respectivamente, sobre o tema: "La legge tributaria, nell'estendere le obbligazioni d'imposta a persone diverse dal soggetto passivo, può fare ancora un passo innan zi, sostituendo completamente al soggetto medesimo, nei rapporti con l'amministrazione finanziaria...". e "Oltre al soggetto passivo dell'imposta, la legge tributaria molte volte didiversa persona che puó denominarsi responsabile d'imposta". 8

\subsubsection{Terceira Posição}

Os partidários dessa terceira corrente sustentam que apenas o contribuinte e o substituto figurariam no pólo passivo da obrigação tributária. Dentre eles, Villegas destaca Blanco Ramos, Cardoso da Costa e Pérez de Ayala. Quanto a esse último, podemos observar em seu clássico Curso de derecho tributario as razōes que o levaram a restringir o caráter de sujeito passivo ao contribuinte e substituto Com efeito sustenta Pérez de Ayja que "es sujetop to, sustenta Perez de Ayala que "es sujeto passivo de la obligación tributaria material aquel que resulta obligado al pago de la deuda tributaria". 9 Evidentemente, o autor refere-se aqui aos obrigados diretos - ou seja, àqueles para os quais nasce a obrigação de recolher o tributo. E o que se depreende da seguinte frase: "Como ya hemos apuntado, se puede ser sujeto pasivo de las prestaciones tributarias (tanto materiales como formales), ya en concepto de contribuyente, ya de substituto del contribuyente ${ }^{m 10}$.

\subsubsection{Quarta e Última Posição}

Para os autores classificados nesta corrente somente podem ser considerados como sujeitos passivos aqueles que pagam, concretamente, 0 tributo ao fisco. Assim, todas as demais pessoas obrigadas a ressarcir não seriam consideradas como sujeitos passivos. Trata-se da corrente na qual podem ser enquadrados A. Berliri te na qual podem ser enquad Cléber Giardino, segundo a classificação de $\mathrm{H}$. Villegas.

\subsubsection{Posicionamento Pessoal}

Se levarmos em consideração as peculiaridades apresentadas pela obrigação tributária veremos que é extremamente dificil negar o status de sujeito passivo tributário ao substituto legal. É que a obrigação tributária exsurge única e exclusivamente da lei, no exato instante em que se verifica sua incidência. Desta forma, a norma juridica que atribui a uma terceira pessoa - não vinculada diretamente ao fato gerador - 0 dever de recolher tributo, encerra, inedor - o dever de recolher tributo, encerra, inevitavelmente, uma previsão legal que quando realizada em concreto determina o nascimento da obrigação imposta ao substituto de recolher o imposto. Parece-nos, pois, assistir plena razão àqueles autores agrupados sob a primeir corrente. De fato, o substituto tributário situase no pólo passivo da relação juridica tributá ria, estando sujeito aos efeitos da prescrição legal tão logo verificada a ocorrência do pressuposto de fato

\subsection{O Conceito de Substituto Tributário.} Elementos Distintivos

Partindo-se da premissa de que o substituto integra, efetivamente, o pólo passivo da obrigação tributária" ${ }^{11}$, cabe-nos agora conceituá-lo, para depois assinalar seus elementos distintivos, o que faremos à luz das mais abalizada lições encontradiças em doutrina.
Alfredo A. Becker, por exemplo, assinala o momento em que se verifica a substituição: "Existe substituto legal tributário, toda a vez em que o legislador escolher para sujeito passivo da relação juridica tributária um outro qualquer individuo, em substituição daquele determinado individuo de cuja renda ou capital a hipótese de incidência é fato-signo presuntivo ${ }^{12}$. Das pade incidencia é lato-signo presuntivo ${ }^{12}$. Das palavras de Becker depreende-se que para o autor o elemento que distingue o substituto reside na
eleição de pessoa diversa daquela vinculada, diretamente, ao fato-signo presuntivo.

Já Rubens Gomes de Sousa, ao definir o substituto tributário, faz repousar seu caráter distintivo na ausência de relação econômica com o ato, fato ou negócio que dá origem à tributação, ou seja, na substituição o tributo é cobrado de determinada pessoa que não tira vantagem econômica desse ato, fato ou negócio. ${ }^{13}$

Por sua vez, Alcides Jorge Costa em tese de doutoramento defendida perante a U. S. P., utiliza como elemento distintivo do substituto a ausência de relação direta deste com o fato gerador, ao contrário do que se passa com o contribuinte ${ }^{14}$

$\mathrm{Na}$ doutrina alienigena merece ser destacada a posição de Dino Jarach a respeito da maté ria. Com efeito, parte o jurista argentino da causa jurídica do imposto - que considera como sendo a existência da capacidade contributiva - para demonstrar que o substituto diferenciase do contribuinte, justamente, em função dessa capacidade econômica. Em outros termos, o contribuinte estaria obrigado por natureza, por titulo próprio, ao pagamento do imposto, pois é em relação a ele que se verificaria a causa impositionis $^{15}$.

Deixamos, por último, a análise de posição de Pérez de Ayala que, com maestria, procura traçar a distinção entre contribuinte e substituto tributário ${ }^{16}$. Para 0 autor os elementos distintivos residem nos seguintes pontos: 1) a obrigacão do contribuinte nasce da lei, tal qual a do substituto, porem, no caso do contribuinte este há de ser titular do fato imponivel, o que não se verifica com o substituto; 2) a determinação legal do contribuinte pode ser efetuada de modo implicito, ao passo que a eleição do substituto depende, necessariamente, de lei que disponha expressamente a respeito; 3) o contribuinte deve 
suportar a carga tributária, tal não ocorrendo antes recomendam, veementemente, sua utilicom o substituto, que tem sempre o direito ao zação. ressarcimento da quantia por ele paga ${ }^{17}$.

\section{TRIBUTAÇÃO NA FONTE}

A tributação da renda na fonte apresenta-se como clássico exemplo de substituiçāo tributária $^{18}$, no qual o recolhimento do imposto fica a cargo daquele que credita os rendimentos aos beneficiários.

De início, cumpre referir que a substituição tributária empregada na retenção na fonte do imposto de renda coaduna-se, inteiramente, com o direito tributário, não apresentando qualquer anormalidade ${ }^{19}$. Pelo contrário. Como veremos a seguir, a utilização da substituição tributária revela-se, muitas vezes, como a única maneira capaz de viabilizar, pragmaticamente, a tributação dos rendimentos auferidos, porquanto estejam esses de tal modo dispersos que a tributação na pessoa do titular resultaria absolutamente impraticável.

Há, por conseguinte, que se compreender a utilização da figura do substituto tributário pelo legislador dentro do contexto histórico em que nos encontramos inseridos ${ }^{20}$. Sem dúvida, temos assistido a uma multiplicação constante das relaçōes econômicas havidas entre os individuos, as quais estão a demandar do direito regulação compativel. Assim, o desenvolvimento das macroempresas, a celeridade do tráfego mercantil, a diversidade das modalidades contratuais, dentre outros fatores, não só justificariam como também exigiriam a utilização da substituição tributária, da qual é espécie a retenção na fonte.

Examinemos, portanto, quais as vantagens que a utilização da substituição tributária proporciona, justificando, dessarte, a larga aplicação que dela fazem a quase totalidade dos sistemas juridicos contemporâneos.

\subsection{Vantagens da Tributação na Fonte}

A técnica da tributação dos rendimentos na fonte foi elaborada pelo direito tributário tendo por escopo, básica e fundamentalmente, assegurar o efetivo recolhimento dos tributos devidos ao Estado ${ }^{21}$. Apresenta, portanto, uma série de vantagens ${ }^{22}$ que não só justificam, mas

\subsubsection{Fatores Psicológicos da Retenção na Fonte}

Dentre as primeiras vantagens apresentadas pela tributação na fonte podemos citar sua maior aceitabilidade no plano psicológico. Evidentemente, tal aspecto não contribui para assegurar a eficácia do recolhimento - fim último do instituto da substituição tributária - todavia, não deixa de ser interessante comentar, brevemente, o fenômeno.

Referem alguns autores, a nosso ver com razão, que a retenção do imposto na fonte produz menor grau de impacto sobre o contribuinte. De fato, a retenção do tributo na fonte pagadora faz com que o beneficiário habitue-se a ver seu rendimento diminuido pelo imposto, considerando-o, já quando do seu recebimento, em valor não é, portanto, sequer computado pelo contrido pelo contribuinte. Este, por não ter de verter parcela de recursos disponiveis de seu patrimônio para 0 Estado, tende a aceitar de forma mais resignada a retenção do imposto devido na fonte ${ }^{23}$.

Ainda procurando examinar os aspectos psicológicos atuantes na tributação na fonte, não poderiamos deixar de referir importante colocacão de Pietro Bodda. Aduz o autor que por não ser o substituto aquele que suporta de fato 0 peso do imposto, esse não se empenharia na ocultação do fato gerador do tributo ${ }^{24}$. Ademais, poder-se-ia acrescentar ainda que a responsabilização do substituto pelo recolhimento do imposto quando da ocorrência do fato gerador. independentemente de ter ele efetuado a retencão na fonte, faria - como em realidade o faz com que a ocultação do fato gerador fosse redu-

\subsubsection{Fatores Econômicos da Retenção na} Fonte

Mas não é só no plano psicológico que se situam as vantagens que estão a justificar o emprego da tributação na fonte. Ao lado dessas encontram-se razões econômicas que, ao contrario das psicológicas, contribuem efetivamente para assegurar a arrecadação dos tributos liquido 0 montante devido a titulo de imposto zida a niveis minimos. devidos. Dentre essas, talvez a mais importante resida na concentração da sujeição passiva tributária assim denominada por Ernst Blumenstein ao escrever: "Ancora egli (o legislador), metein ao escrever: "Ancora egli (o legislador), mediante il prelievo dellimposta alla sorgente può limitare il numero dei soggetti di imposta per una pluralità di casi

Evidentemente, a concentração da sujeição essiva em poucas pessoas facilita enormemenimpostos devidos ao Estado. Imaginemos, para que se demonstre a vantagem apresentada pela tributação na fonte nesse particular, a distribuição de dividendos de uma grande companhia a milhares de acionistas. Nessa situação, caso não fosse adotada a retenção na fonte da parcela devida por cada um dos um dos acionistas a titulo de imposto de renda tornar-se-ia dificilimo - senão impossivel recolher, individualmente, o tributo devido. $\mathrm{E}$ mais, existindo ações ao portador ${ }^{26}$ - cujo titu lar, por ser o detentor, nem sempre se conhece (sua transferência opera-se pela mera tradição) - a tributação na fonte apresentar-se-ia não so vantajosa do ponto de vista econômico, mas sim como ún como única forma de viabilizar a tributação

rendimentos percebidos pelos acionistas.

No caso especifico do imposto de renda a tri-
butação na fonte representa, sem dúvida alguma, importantíssimo mecanismo à disposição da administração fazendária. Dentre os aspectos econômicos a destacar vale referir ainda, além da comodidade 27 que advém de sua utilizaça da comodidade pertância que a tributação na fonte representa para 0 equilibrio das contas públicas. Essa deve-se às entradas periódicas e sucessivas de divisas para o Estado, que lhe permitem fazer frente às despesas à medida em que estas vão ocorrendo.

Mas há ainda outro importante aspecto econômico que motiva o emprego da tributação na fonte pelo direito tributário. Trata-se do fato de encontrar-se o substituto em contato direto com a prestação pecuniária que deverá ser vertida aos cofres públicos. Ou seja, tributa-se o fato ou situação juridica objeto da obrigação tributária na primeira oportunidade em que isto se faz posivel, isto $\dot{c}$ antes que o imposto seja disfaz possivel, isto e, antes que o imposto seja disperso, assegurando-se, assim, o seu recolhimento ${ }^{28}$

\subsection{Críticas à Tributação na Fonte}

Não obstante sejam evidentes as vantagens que a tributação na fonte apresente, alguns autores têm formulado críticas ao emprego dessa modalidade de substituição tributária, as quais podem ser encontradas na introdução que faz 0 Prof. Furio Bosello à sua monografia sobre 0 tema da que a primeira critica oferecida à tributação na fonte residiria na alegada "ilusão financeira" imposta ao beneficiário dos rendimentos, eis que esse não se aperceberia do efetivo ônus do imposto.

Com efeito, tal critica nos parece absolutamente infundada, porquanto aquele que suporta economicamente o pagamento do imposto tem o conhecimento do quantum retido para essa finalidade. Ademais, se contrapormos esta "critica" às inúmeras vantagens que a retenção na fonte encerra, veremos, com maior clareza ainda, seu absoluto despropósito.

A segunda critica relatada por Furio Bosello apresenta-se mais consistente. Haveria, em sua opinião, uma incompatibilidade entre a tributação na fonte e o respeito às condiçōes pessoais do contribuinte. Assim, para os adeptos desta posição, a tributação na fonte não levaria em consideração a capacidade contributiva do beneficiário ${ }^{30}$, posto que seriam os rendimentos tributados sem atendimento ao critério da progressividade.

No entanto, apesar de existir boa dose de razão nesses argumentos, pode-se afastar, fa cilmente, esse aparente "desrespeito" às condições pessoais do contribuinte. No que diz respeito à progressividade é perfeitamente possive aplicá-la na tributação na fonte, tal qual aliás é hoje feito no Brasil. Já no que concerne à observância das condições pessoais do titular dos rendimentos, basta que a legislação preveja uma maneira de realizar, em períodos de tempo determinados, um acerto das quantias recolhidas na fonte, estipulando, quando for o caso, a restituição do imposto recolhido. Desta forma, atender-se-iam as peculiaridades de cada contribuinte, não subsistindo razão para que se deixas se de aplicar a tributação na fonte.

A última critica transcrita na obra de F. Bosello ${ }^{31}$ apresenta argumentos tão débeis quanto 
aqueles constantes da primeira. Fundamentase na capacidade da administração de efetuar um rigoroso controle da percepção dos rendimentos das pessoas, sendo, pois, desnecessária mentos das pessoas, sendo, pois, desnecessária
a adoção da tributação na fonte. Quanto à essa a adoção da tributação na fonte. Quanto à essa
critica parece que a oposição mais certeira não advèm dos livros de doutrina, mas da observação do curso natural da história, que tem demonstrado a constante ampliação da tributação na fonte ${ }^{32}$ mesmos naqueles paises que atingiram alto grau de mecanização, como refere $\mathrm{Bo}$ ram alto
sello.

\subsection{Legalidade e Tributação na Fonte}

\subsubsection{Necessidade de Lei Expressa} Estabelecendo a Substituição

Consoante já referimos ao examinar o conceito de substituto (ponto 2.2 ), a sujeição passiva tributária somente se estabelece por lei ${ }^{33}$. Dessarte, na eleição do substituto faz-se imprescindivel a existência de disposição legal expressa que a determine, ao contrário do que se passa na definição do contribuinte, que, muitas vezes, vem estabelecida implicitamente na lei, decorrente da realização do fato previsto na hipótese legal (v.g. a obrigação do proprietário de pagar o imposto sobre seu bem imóvel, muito embora a lei não precise definir quem seja proprietário).

Dino Jarach, a propósito, ao desenvolver esse tema, assinala que a atribuição do fato imponivel ao contribuinte pode ser feita com fundamento em critério exclusivamente econômico, ao passo que, nas demais hipóteses de sujeição passiva indireta, seria sempre necessária a existência de lei estabelecendo esta atribuição $0^{34}$

Aliás, nesse particular - exigência de lei expressa no estabelecimento da substituição parece inexistir divergência doutrinária, tal qual refere Henry Tilbery ao longo de seu já citado artigo ${ }^{35}$

Em assim sendo, restaria por enfatizar, unicamente, que a substituição tributária não decorre da realização do fato previsto abstratamente na hipótese legal da norma impositiva, mas sim da incidência da norma tributária que de-
termina a substituição tributária quando verificada em concreto dada situação. Tal exposição pode ser encontrada com maior riqueza de detalhes na obra de Pérez de Ayala, intitulada Las tor examina a definição legal do sujeito passivo tributário ${ }^{36}$.

\subsubsection{Ineficácia da Substituição}

Estabelecida por Particulares Perante o Estado

Como já explanado anteriormente, a determinação da substituição tributária depende, necessariamente, de lei expressa dispondo a respeito. Desta forma, fácil deduzir que a estipulação por particulares de pretensa "substituição tributária" - no caso do imposto de renda, de alguém obrigado à tributação na fonte - não produzirá qualquer efeito perante a administrap̧ão.

Se partirmos da exata compreensão do nascimento da obrigação tributária - que opera-se sempre ex vi legis - perceberemos, com meridiana clareza, que os particulares não têm $o$ condão de eleger os substitutos tributários. Assim, qualquer disposicão contratual neste sentido apresentar-se-á absolutamente ineficaz perante a administração, e a ela inoponivel. Este aliás, o conteúdo do artigo 123 do C.T.N. ${ }^{37}$

Todavia impende ressaltar tratar-se aqui de ineficácia perante o fisco, e não de nulidade. No plano privado terá surgido a obrigação daquele que se quis eleger "substituto" ao pagamento do seja a mesma inoponivel à administração. A obrigação, portanto, não obstante seja incapaz de produzir efeitos no plano da relação tributária, será vảlida e eficaz entre os particulares ${ }^{38}$.

\subsection{Natureza Jurídica da Substituição -} Tributação na Fonte

A importância de se precisar a natureza juridica da substituição tributária justifica-se pois permite identificar qual o regime juridico que the é aplicável. Assim, analisaremos, nos limites que 0 trabalho impõe, quais as teorias formuladas pelos doutrinadores, expondo, conco-

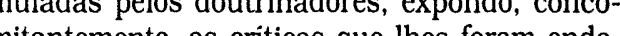
reçadas.

\subsubsection{Teoria da Execução Contra Terceiro}

Os arautos desta teoria - dentre os quais destacam-se Pugliese, Blumenstein e Tesoro entendem que a substituição pode ser considerada como forma de execução contra terceiros estabelecida pela lei. Essa seria análoga, como escreve Pietro Bodda, à execução que o Fisco poderia empreender contra o terceiro, com base em normas processuais de direito comum, após ter notificado o título executivo ao devedor efeti$\mathrm{vo}^{39}$.

As criticas opostas a essa teoria podem ser assim resumidas: a) inexistiria titulo executivo a legitimar a pretensão executiva do Estado; b) haveria uma execuçāo contra terceiro (substituto) sem que a obrigação houvesse deixado de ser adimplida pelo sujeito passivo originário tal qual ocorreria na retenção na fonte; c) teríamos que considerar a existência de duas relamos que considerar a existencia de duas rela-
çoes: uma entre a administração (credor) e 0 contribuinte (devedor) e outra entre esse últim (na posição de credor) e o substituto (como de vedor), o que, todavia, não pode ser admitido genericamente ${ }^{40}$. Por seu turno, Pietro Bodd assinala que os defensores dessa teoria parecem ter considerado unicamente a relação exis tente entre o substituto e substituido, olvidantente entre o substituto e substituido, olvidan-
do-se, contudo da relação entre Estado e substituto, que, segundo esse autor, seria a mais importante para a determinação da natureza juridica da substituição tributária ${ }^{41}$.

\subsubsection{Teorias do Substituto Como} Intermediário e Como Órgão de

Arrecadação

Defendidas, respectivamente, por Bühler Myrbach-Rheinfeld, ambas negam ao substituto a qualidade de devedor do imposto, reduzindo-o, no primeiro caso, à figura do intermediá do-o, no primeiro caso, a no outro, considerando-o como órgão de rio, e, no ou

arrecadação.
$\quad$ Os argumentos dirigidos contra essa teoria centram-se, justamente, na negativa do caráter de devedor do imposto por ela propugnada. A propósito, anota A. D. Giannini que tais teorias näo podem se possui apenas a função econômica de reter e recolher o tributo por conta do ente público, ma é, juridicamente, o único devedor do tributo ${ }^{42}$.
Ademais, conforme faz notar P. Bodda, a consideração do substituto como intermediário teria de pressupor, necessariamente, a existência de obrigazão entre o substituído e o Estado. quando verifica-se justamente o invers $0^{43}$.

\subsubsection{Teoria da Representação "Ex Lege"}

Esta terceira teoria, que tem seu expoente em Uckmar, define a substituição tributária como modalidade de representaçăo ex lege, servindo-se, para tanto, como exemplo, da associação profissional legalmente reconhecida. Consoante sustentam seus autores, a substituição poderia ser considerada como representação de direito público, diversa, todavia, daquela de direito privado 44 .

As críticas formuladas a essa teoria encontram-se bem detalhadas no já citado artigo de P. Bodda, dentre as quais destaca-se a dúvida manifestada pelo autor sobre a possibilidade de surgirem obrigaçōes para o representante (no caso o substituto) quando do exercicio normal da representação, o que, à toda evidência, seria incompativel com os fundamentos basilares desse instituto.

\subsubsection{Teoria de Pietro Bodda}

Segundo entendemos do artigo de Bodda, 0 autor, após criticar as teorias até então existen tes em doutrina, propõe a seguinte solução para tão intricado tema. Parte ele da observação de que o natural è que a obrigação tributária surja, originariamente, entre o Estado e o titular do fato econômico (e cita o exemplo do acionista), podendo, no entanto, ser este "sujeito passivo por excelência" substituido - no interesse da arrecadação - por um terceiro.

Observa o mestre italiano que essa substituição realizada pelo legislador apresenta-se de forma bastante peculiar, porquanto trate-se de uma figura autônoma compreendendo o agir em nome próprio, porèm com eficácia sobre a esfera juridica de outrem. Verifica-se, por conseguinte, tal como fora ressaltado por Pérez de Aya$\mathrm{la}^{45}$, que Bodda procura estruturar a substituicão tributária com base na substituição de direito público.

Quanto às criticas, impende referir a de Pérez de Ayala, que considerou pouco elaborada 
tal teoria, além, é claro, da manifestada por Giannini, segundo o qual o substituto, ao pagar o imposto, não estaria agindo com eficácia sobre a esfera de direitos de outrem (substituido), mas, pelo contrário, em função de obrigação que lhe é própria, pessoal.

\subsubsection{Teoria de Giannin}

Após expor e refutar todas as teorias supra referidas, Giannini propõe sua solução para o problema que vai no sentido de considerar a substituição tributária como "figura tipica del diritto tributario, cui ben poco lume può venire dal riavvicinamento con altri istituti del diritto pubblico o privato, sostanziale o processuale" ${ }^{m 6}$.

\subsubsection{Teoria da Ordenação de Crédito}

Tal teoria, defendida por Nicola d'Amati ${ }^{47}$, sustenta que a substituição caracterizar-se-ia por uma cessão do débito do contribuinte perante a Fazenda ao substituto. Assim, a obrigação originária, havida entre 0 Estado e o contribuinte (sujeito passivo direto), transformar-seia em obrigação entre o Estado e o substituto.

$O$ defeito apresentado por essa teoria pode ser vislumbrado com facilidade se tomarmos como exemplo a substituição tributária nos impostos diretos, $v$. $g$. imposto de renda na fonte sobre dividendos. Na hipótese, inexiste obrigação passivel de cessão, pois esta surgiria já de inicio contra o substituto.

\subsection{O Direito de Regresso do Substituto}

\subsubsection{Considerações Preliminare}

Se considerarmos os motivos que levam o legislador a determinar a sujeição passiva indireta observaremos que o direito de regresso que dai exsurge, em beneficio do substituto, resulta de uma necessidade de assegurar-se o suporte da carga fiscal por aquele que encontra-se diretamente vinculado ao fato econômico que se pretende gravar.

Nesse sentido a lição de Ezio Vanoni: "Il responsabile ed il sostituto che hanno eseguito 'obbligazione in base ad un vincolo stabilito unicamente nell'interesse della imposizione hanno diritto di farsi rimborsare integralmente da colui sul quale, secondo il sistema della legge, il tributo deve in definitiva gravare". 48

Resolve-se, portanto, pelo direito de regresso, aquela aparente "anomalia" mencionada por Pérez de Ayala ao tratar da substituição tributária. 49

Restaria assinalar, ainda, que o direito de regresso pode operar-se no plano interno ou externo, classificação essa encontradiça nas bres denst Blumenstein e Ezio Vanoni, denre outras. Na hipótese sub examine - substituição (tributação na fonte) - tratar-se-ia de regresso externo $0^{50}$, já que esse seria exercido contra alguém não integrante da relação tributária originária.

\subsubsection{Direito de Regresso e Recolhimento de} Quantia Indevida

Interessantes questōes se apresentam quando analisamos as conseqüências juridicas que 0 recolhimento de "tributo indevido"51 produziria, tanto em nivel do substituto quanto do substituido. Poderia o substituto exercer seu direito de regresso contra o substituido exigindo-the 0 tributo" por ele recolhido de forma indevida? "unem estaria legitimado a re petir indébito recolhido: substituto, substituido, ou ambos? São essas as indagações que procuraremos responder, separadamente, nas linhas seguintes.

Para que possamos resolver a primeira questão, imperioso responder, preliminarmente, a outra pergunta: tem o substituto o dever de zelar pela estrita legalidade da obrigação tributária, isto è, está ele obrigado a verificar se a norma impositiva foi corretamente aplicada pela informação?

Ao discorrer sobre o tema ressalta P. Bodda que se considerássemos o substituto como sendo obrigado a zelar pelo recolhimento do tributo, nos moldes fixados pela lei, teriamos de reconhecer seu status de representante do substituído, pois esse teria de agir dentro dos limites do mandato que lhe fora outorgado 52 . Despicicriticas das anteriormente, e que levaram $P$. tão $0^{53}$

Sustenta, assim, que o substituto poderia voltar-se contra o substituido ainda que hou- vesse recolhido "tributo indevido", fundamentando sua opinião na presunção absoluta de legitimidade que entende acompanhar o lançamento, enquanto ato administrativo. ${ }^{5}$

Por outro lado, Clementini, Bertelli e Scandale, citados por P. Bodda, adotam posicionamento diverso, entendendo não assistir direito de regresso ao substituto que houvesse recolhido "tributo indevido" 55 .

Particularmente, parece-nos que assiste razão àqueles que respondem negativamente à primeira questão suscitada, pelos seguintes fundamentos: a) mesmo que se fale em presunção de legitimidade do lancamento - decorrente de sua natureze gumenta Bodda, essa praesumptio (como o próprio termo indica) comportaria prova em contrário, a qual poderia ser produzida na via do processo administrativo. Logo, tal presunção de legitimidade - que não se pretende aqui negar - poderia ter sido desfeita caso houvesse o substituto observado a mínima diligência quando do recolhimento da exação; b) também o chamado auto-lançamento - no qual o contribuinte desenvolve toda atividade sem qualquer participação da administração - estaria a justificar a impossibilidade do substituto voltar-se regressivamente contra o substituido. Tomemos, como exemplo, a retenção do imposto de renda na fonte sobre salários. Neste caso, o pagador dos salários limita-se a calcular o montante do imposto rios limita-se a calcular o montante do imposto
de renda devido, retê-lo e repassá-lo aos cofres de renda devido, retê-lo e repassá-lo aos cofres
públicos. Perguntar-se-ia aonde estaria a "presunção de legitimidade do lançamento" a que Bodda se refere; c) além disso, parece-nos existir outra razão ainda mais contundente para justificar a impossibilidade do substituto de reJusticar a impossilidade do substituto de re embolsar-se mento de "tributo indevido". Se tivermos presente que a obrigação tributária somente surge da lei, ou seja, tem seu nascimento condicionado à previsão legal do fato que irá desencadeáa, veremos que esta quantia recolhida a mais pelo substituto não é tributo, pois não teve oripelo substituto năo é tributo, gem na lei tributária. Dessa forma, não se trataria de pagamento de "tributo indevido" pelo substituto, mas de quantia recolhida indevidamente e que pode revestir-se de qualquer outra natureza, exceto, justamente, a de tributo. Assim, o recolhimento dessa quantia indébita refugiria ao âmbito da relação tributária, não de- vendo aplicar-se, por conseguinte, a técnica da substituição que fora criada, frise-se bem, para permitir o ressarcimento do tributo, o que, à toda evidência, não ocorreria in concreto.

Passemos, agora, para concluir este ponto ao exame da legitimidade ativa na repetição deste indébito. A questão posta indaga quem teria legitimidade para requerer a restituição da quantia indevidamente recolhida: o substituto ou 0 substituido? Alfredo A. Becker analisou magnificamente o tema, sustentando variar a solução do problema em função da existência ou não de repercussão jurídica prevista em lei. Estando presente a repercussão jurídica, por reembolso ou retenção, não poderia o substituto solicitar a restituição ${ }^{56}$. E exemplifica com a distribuição de dividendos de uma sociedade anônima, na qual fora retido indevidamente o Imposto de Renda na Fonte. A legitimidade da sociedade (que tem repercussão juridica - da espécie retenção) para requerer a restituição dependera da comprovacao de que essa suportou o encargo fiscal, não tendo descontado o valor retido dos acionistas ou provando tê-lo devolvido. Já os substituidos poderão pleitear a repetição desde que comprovem ter arcado com o ônus do "imposto" indevido. Trata-se, em sintese, de verificar quem foi economicamente prejudicado pelo recolhimento indevido, ou, como diz $\mathrm{H}$. Villegas, de procurarmos aquele que, efetivamente, empobreceu ${ }^{57}$

\subsection{Responsabilização do Substituído}

Por derradeiro, analisemos agora outra interessante questão que o estudo da substituição tributária suscita: poderia o Estado voltar-se contra o substituido quando o tributo não fosse recolhido pelo substituto?

Também nesse ponto divergem os autores. A. D. Giannini entende pela negativa, sustentando: "a me pare che il carattere cogente delle disposizioni tributarie si affermi anche in questo caso e induca, quindi, ad adottare la soluzione negativa". ${ }^{58} \mathrm{~A}$ seu turno, Bodda refere que não obstante não possa a Fazenda voltar-se diretamente contra o substituído (pois este não integraria 0 pólo passivo da relação tributária) ha que se observar a finalidade última desse instituto - consistente em agilizar e garantir o recolhimento dos tributos. Assim, Bodda pare- 
ce propor uma espécie de responsabilização do substituido quando do não recolhimento do tributo pelo substituto, condicionada, todavia, à inexistência de retenção anterior.

Em posição extremada, Dino Jarach defende a faculdade do Estado de demandar do substituido o pagamento do tributo, ainda que já houvesse sido feita a retenção na fonte. Em suas palavras: "O contribuinte em caso de substituição não è indiferente para o direito tributário, não é somente uma figura teórica, abstrata, de ordem ético juridica, melhor que jurídico-positiva, como erroneamente foi afirmado, senão que se manifesta seja no direito de exigir o pagamento do contribuinte, direito que existe sempre para substituto mesmo que a lei não o disponha expressamente, seja no fato de que, se a lei não dispõe o contrário, a administração poderá sempre fazer valer o crédito tributário contra o contribuinte, quando o substituto resulte insolvente, mesmo que este se encontre insolvente depois de haver exigido o pagamento do contribuinte".

A nosso ver, tal posição apresenta-se profundamente incompativel com o minimo senso de justiça. Ora, se o Estado - procurando assegurar a maior eficácia possivel na arrecadação dos impostos - utiliza-se da substituição tributária (inserindo como sujeito passivo da obrigação pessoa diversa daquela que normalmente deveria ser considerada), não faria sentido que o substituído fosse prejudicado tão injustamente, sendo obrigado a pagar duas vezes o mesmo imposto. A situação seria diversa, evidentemente, no caso de ter inocorrido a repercussão do tributo sobre o substituido, quando, então, a sua responsabilização não atentaria contra a razoabilidade (Recasénc Siches) minima que se espera do direito.

\section{CONCLUSÕES}

Nosso entendimento pessoal sobre cada um dos aspectos e questões suscitadas encontra-se disperso ao longo do texto. Destarte, restaria aqui apresentá-los, sistematicamente, tal qual azemos a seguir:

6.1. A classificação proposta por Rubens Gomes de Sousa dos sujeitos passivos da obrigação tributária foi incorporada pelo C.T.N. no art. 123, situando-se tanto o contribuinte quanto o substituto (que o Código engloba na figura do responsável) no pólo passivo da obrigação tributária.

6.2. A compreensão da dinâmica de atuação da norma tributária - fundada na realização concreta da hipótese legal - leva-nos, indubitavelmente, a considerar o substituto tributário como sujeito passivo da obrigação, já que esta surge, diretamente, contra ele.

6.3. O substituto tributảiro distingue-se do contribuinte pois este último é o titular do fato imponivel, estando diretamente vinculado ao lato-signo presuntivo de riqueza (terminologia de Alfredo A. Becker), ao passo que o substituto encontra-se ligado ao fato gerador não por sua natureza, mas por força de disposição legal expressa.

6.4. A tributação na fonte não só pode como deve ser empregada pela administração, não apresentando nenhuma anormalidade, desde que respeitada a repartição de competências impositivas erigidas à nível constitucional.

6.5. A técnica da tributação na fonte apresenta inumeras vantagens para a administraça, dentre as quais destacam-se uma maior comodidade, segurança e agilidade no recolhimento dos tributos.

6.6. As criticas opostas à tributação do imposto de renda na fonte não são bastantes para ustificar sua não utilização. A principal delas - de que a tributação na fonte não relevaria as condições pessoais do contribuinte - pode ser superada desde que efetuado, periodicamente, um acerto das quantias recolhidas na fonte com os valores devidos a título de imposto, após terem sido consideradas as peculiaridades do substituido.

6.7. A substituição tributária somente pode ser estabelecida por expressa disposição de lei, sendo ineficazes perante a administração as convenções dos particulares, que dão lugar, unicamente, a obrigaçōes no plano das relaçōes privadas.

6.8. O direito de regresso do substituto apresenta-se absolutamente indispensável para que se possa sanar a aparente "anomalia" que a substituição tributária encerra, porquanto faz repercutir, juridicamente, sobre o substituido, 0 ônus do tributo.

6.9. O substituto tem o dever de zelar pela estrita legalidade do tributo recolhido, fazendo- o na quantia estipulada em lei, sob pena de não poder exercer o regresso contra o substituido.

6.10. A administraçāo somente poderá volar-se diretamente contra o substituido se esse não houver sofrido a retenção na fonte e se 0 substituto não houver recolhido o tributo devido. Na hipótese do substituto efetuar a retenção na fonte e não repassar o tributo retido ao Fisco esse não poderá coactar o substituído a um duplo recolhimento.

\section{NOTAS DE REFERÊNCIA}

1 Evidentemente, o estudo da sujeição passiva tributária è imprescindivel para que se possa estudar a substituição tributária.

2 São Paulo, ed. Revista dos Tribunais, pp. 107, 1980. 30 autor elenca ainda os autores que não se amoldam a nenhuma destas quatro correntes.

4 Dentre os autores estrangeiros Villegas elenca como adeptos da primeira corrente Pugliese, Giuliani Fonrouge, Flórez Zavala, Saccone, Ingrosso e De La

5 Compêndio de Legislaçāo Tributária, ed. póstuma, São Paulo, ed. Resenha Tributária, 1975. pp. 92.

6 Rubens Gomes de Sousa subdivide ainda a trasnferència em sucessä,
dade, op. cit.. p. 93 .

7 Instituzioni di Diritto Tributario, 5.ed., Milano, Dott.

A. Giuffrè - Editore. pp. 107, 1951.

8 Op. cit., p. 105.

9 Curso de derecho tributario, tomo I, 2.ed., Madrid, Editoriales de Derecho Reunida S/A, pp. 255, 1978. 10 Op cit. 255

11 Dessarte, deixaremos de referir conceituaçoes elaboradas por autores que não atribuam ao substituto o status de sujeito passivo da obrigação.

2 Teoria Geral do Direito Tributário, 2.ed., ed. São Paulo, Saraiva, pp. 503, 1972.

3 Op. cit., p. 93

14 Contribuição ao Estudo da Obrigação Tributária. Tese de doutoramento apresentada à Faculdade de Direito da Universidade de São Paulo, 1972, São Paulo, pp. 65. Sem dúvida, merece ser tambèm destacada a utilização da teoria obrigacional dualista no âmbito da obrigação tributária. Com efeito, consoante relata o Prof. Alcides Costa em sua tese, a distinção formulada pela doutrina alemã entre debi tum (schuld) e obligatum (haftung) revela-se extremamente importante para a compreensão do fenômeno da responsabilidade e substituição tributárias. No mesmo sentido Ricardo Lobo Torres em Curso de direito financeiro e tributário, Rio de Janeiro, ed. Renovar, 1993, pp. 207 e ss.

5 O Fato Imponível, São Paulo, ed. R. T., pp. 156/163,

16 Op. cit., pp. 251-6.
17 A nosso ver a opinião de Pérez de Ayala não está correta neste particular - quando utiliza como elemento de distinção o suporte efetivo da carga tributária. E pelo seguinte motivo: também o contribuinte pode transferir o encargo fiscal a outras pessoas, sem deixar, contudo, de ser considerado como contribuinte. E o que se dá, efetivamente, com a quase totalidade dos tributos que comportam a
translaçáo do ônus fiscal para os consumidores finais. Assim, parece que a distinção entre substituto e contribuinte não deve repousar, a nosso ver, no fato do contribuinte suportar - economicamente - a carga fiscal, porquanto isto geralmente não ocorra, em realidade. Caberia distinguir aqui, tal qual faz A.A. Becker, a repercussão econômica da juridica.

Preleciona Ernst Blumenstein: "Per la sua natura giuridica, l'imposizione alla sorgente ha la massima ma di Diritto Delle Imposte, Milano, Dott. A Giuffrè. pp. 66,1954

19 A propóito leciona Alfredo A. Becker: " os fatores que acabaram de ser apontados estão induzindo 0 legislador a escolher um outro individuo para a posição de sujeito passivo da relação juridica tributária. E este outro individuo consiste precisamente no substituto legal tributário cuja utilização, na época atual, já é frequentissima, 'de tal modo que, dentro de alguns anos, o uso do substituto legal pelo legislador será a regra geral". Teoria geral do direito tributário, 2.ed., São Paulo, ed. Saraiva, pp. 502,1972

20 Pietro Bodda refere em seu artigo Il sostituto d'imposta, que a primeira menção à substituiçāo tributária na Itália deu-se em 1877 com a lei do imposto de renda que estabelecia às pessoas juridicas e outros órgãos a obrigatoriedade de recolher aos cofres públicos o imposto correspondente aos rendimentos que por elas fossem creditados. in: JUS - Rivista di Scienze Giuridice, ano II - fascicolo II. Milano, pp. 192 e ss, 1941

21 Indicando a principal razão que levou o legislador a adotar a substituição tributária manifesta-se Pietro Bodda. "Ed è evidente la ragione che ha spinto legislatore a cosi comportarsi. assicurare il piu possible lade a ciesi con the Op. cit., p. 196. Op. cit., p. 196.

da da substituiçáo legal tributária, in: Direito Tributário 2, São Paulo, ed. José Bushatsky, 1972, esboça uma prego da substituição tributária, o qual, entretanprego da substituiçáo tributária, o qual, entretanas vantagens decorrentes da imposição na fonte em psicológicos e econômicos, sem deixar de ressalta que tal divisão atende à finalidades meramente expositivas e que não retiram deles a relevância para o direito. 
23 Nesse sentido pronunciou-se Héctor Villegas em conferência publicada na Revista de Direito Tribu-
tário, vol. 6, ed. R. T. 1986, São Paulo, pp. 68, Retencáo de tributos-agentes de retencão e a 68 , Re percepsão: "Aos olhos de muitos contribuintes, percep̧a . "Aos on te multos contribuintes, mediante a retençáo, o tributo passa a ser completamente dissimulado; e o trabalhador que recebe um
salário diminuido pelo valor retido acostuma-se considerar seu salărio $\mathrm{em}$ valores liquidos; o considerar seu salario em valores liquidos; o que
paga, o patrão - que paga e dever reter - acostupaga, o patrão - que paga e dever reter - acostu-
ma-se a fazer um cálculo global, em que inclui seus proprios impostos, aos quais acrescenta os impostos de seus subordinados, que retém, e os montantes da previdência social que também retém".

24 Op. cit., pp. cit.

25 Op. cit., p. 58. Nesse diapasão também A. D. Giannini, op. cit. pp. cit.: "... il vantaggio che deriva all'amministrazione finanziaria dalla possibilitá compiere gli atti di accertamento e di riscossione del tributo in confronto ad una persona sola, anzichè ad una pluralità di contribuenti".

26 Não desconhecemos que atualmente inexistem açōes ao portador por força da Lei no 8.021 de $12-4-90$

contudo, cremos ser válida a referência.

que a substituica tributária propo a comodidade que a substituição tributánla proporciona à admto piú comodo tassare un reddito su di una sola persona....". Op. cit., p. 199.

28 Também essa razão é mencionada por P. Bodd "Inoltre è opportuno quando sia possibile colpire reddito alla sua stessa fonte per evitare che con l'ulteriore suo impiego, esso possa disperdersi e non sia più percepibile l'ammontare dell'imposta". sia piu percep
cit., pp. cit.

29 Il Prelievo Alla Fonte Nel Sistema Della Imposizione Diretta. Padova, ed. CEDAM, pp. 5 e ss, 1972.

30 A propósito escreve Pérez de Ayala: "... si nosotros consideramos que, dentro de una correcta técnica tributaria, el tributo debe gravar siempre al titular de la capacidad contributiva, es decir, al titular del hecho imponible tal y como lo hemos definido, entonces parece lógico entender que la figura de la sustitucion tributaria es, en cierto modo, una anomalia que supone siempre una lateración de los principios lógicos que disciplinam la aplicación del trbuto". Op. cit., p. 256

31 Importante frisar que F. Bosello rebate todas as criticas formuladas à tributação na fonte e que sua obra foi utilizada por referir, justamente, o teor dessas criticas.

32 Furio Bosello. Op. cit., p. 10

Daí falarmos em legalidade e substituição tributáTa. Sem dúvida o pricipio da legalidade apresentante estatal, tendo, como demonstrou o Prof Cerd Willi Rothmann, estreita vinculacão com o Estado de Direito. Em assim sendo, também no âmbito da responsabilidade tributiria faz-se sentir a presenca imprescindivel da legalidade tributária. in: $O$ Princi pio da Legalidade Tributária, Direito Tributário, $5^{\text {a }}$ coletânea, São Paulo, ed. José Bushatsky, 1973. O Fato Imponivel. São Paulo, ed. R. T., p. 164, 1989. Ernst Blumenstein a respeito da imprescindibáo de de de lei expressa prevendo a substituiçáo tributária: "Tutti questi obblighi di terze persone no sorgono, a differenza di quelli del soggetto di imposta, da una diretta relazione con l'oggetto d'imposta e dalla appartenenza tributaria all'ente pubblico. Di conseguenza essi possono essere considerati solo allorquando siano previsti espressamente dalla legge" Op. cit., p. 59.

36 Editorial de Derecho Financiero, Madrid, pp. 86-7, 1970

37 "Art. 123 - Salvo disposiçōes de lei em contrário as convençōes particulares, relativas à responsablidade pelo pagamento de tributos, não podem ser opostas à Fazenda Publica, para modificar a definição legal do sujeito passivo das obrigaçōes tributáias correspondentes"

Nesse sentido preleciona Blumenstein: "La assunzione di obblighi di diritto delle imposte da parte di un terzo attraverso accordi contratuali, come avviene spesso in certi negozi giuridici di diritto privato, no costituisce sostituzione di imposta e non puó di questa. Essa dà origine piuttosto unicamente ad un obbliro di diritto privato del terzo a rimborsare a contribute una imposta che elli deve pagare.

Op. cit p 205

Pérez de Ayala.

Op. cit., p. 258. Giannini também critica tal teoria. Op. cit., p. 109.

41 Op. cit., p. 205.

43 Op. cit. p. 207.

44 Assevera Uckmar que a representação de direito privado pressupõe incapacidade do representado, ao contrário da de direito público. E que, além disso, da representação de direito privado não exsurgiriam obrigaçoes ao representante que se ativesse aos limites do mandato, diversamente do que ocorreria na representação de direito público.

45 Op. cit., p. 259

46 Op. cit., p. 110

47 Apud Përez de Ayala. Curso, pp. cit.

Opere Giuridiche, v. II, Milano, Dott. A. Giuffrè Edtore, pp. 208-9, 1962.

Op. cit., p. 256. v. nota rodapé $\mathrm{n}^{\mathrm{9}} 30$

Op. cit., pp. 68-69 e op. cit., pp. 209-10, respectivamente. Interessante notar que Blumenstein coloca o direito de regresso advindo da substituição como sendo interno, ao contrário de Vanoni, que o classiheve-se a fato ristico do regresso interno a possibilidade daquele sob o qual o direito de regresso vem exercido de integrar pessolmente a obrigacão tributária origenária ao contrário do que sustenta Vanoni, que utliza como elemento distintivo do regresso interno o fato de operar-se entre aqueles co-obrigados ao pagamento do imposto, v.g. devedores solidários.

51 Adiante veremos porque não se pode falar em tributo indevido.

53 Todavia, P. Bodda não deixa de apresentar a problemática que a adoção dessa posição encerra, principalmente devido ao fato do substituido encontrarse à margem da relação obrigacional estabelecida entre 0 substituto $\mathrm{e}$ a administraçao, nảo recebendo quaisquer avisos, notificaçoes, etc.

54 Em suas palavras: “... ocorre tenere presente che nel caso, poichè il reddituario non è più in termini per ricorrere, sussiste un atto amministrativo di accertamento che ha, per esso almeno, ormai una presunzione assoluta di legittimità, onde non si vede come si possa ancora parlare di comportamento negligente del sostituto che dà luogo ad un atto illegitimo pregiudicante al redituario". Op. cit., p. 220.

Os argumentos empregados por Becker para atingir ta $524-28$ de sua obra ja citada nas $524-28$ de sua obra ja citad

58 Op: RDT. $6 / 78$, $p .7$

\section{BIBLIOGR AFIA}

AYALA J.L.P. de. Curso de Derecho Tributário, tomo I, Editorial de Derecho Financiero - Editoriales de Derecho Reunidas, 2.ed

. Las Ficciones En El Derecho Tributario. Madrid,

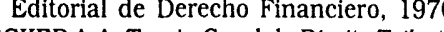

Direito Tributário, 2.ed. São Paulo, Saraiva, 1972.

ma Diritto Delle Imposte. Milano. Dott. A. Giuffrè - Editore, 1954.
BODDA P. Il Sostituto d'Imposta. In: JUS - Rivista di Scienze Giuridiche, anno II - fascicolo II, Milano,

BOSELLO F. Il Prelievo Alla Fonte Nel Sistema Della Imposizione Diretta. Padova, CEDAM, 1972

STA A.J. Contribuição ao Estudo da Obrigacão Tributária. Tese de doutoramento apresentada à Faculda Universidade de São Paulo, São Paulo, 1972.

çaço Tributária. In: Curso de direito triPaulo, Saraiva, 1982

1. $11^{a}$ tiragem da $4^{a}$ ed. São Paulo, Resenha Tributária, 1986.

ANNINI. Instituzioni Di Diritto Tributario, 5.ed., Milano, Dott. A. Giuffrè Editore, 1953.

RACH D. O Fato Imponivel, 1.ed. São Paulo, R. T., 1989.

G.W. O Principio da Legalidade Tributária. In: Direito Tributário, $5^{\underline{a}}$ coletânea. Sảo Paulo, José

SOUSA R.G. Compêndio de Legislação Tributária. ed. postuma. São Paulo. Resenha Tributaria, 1975.

butária In Direito Tributário 2 São Paulo, José Bushatsky, 1972.

TORRES R.L. Curso de Direito Financeiro e Tributário. Rio de Janeiro, Renovar, 1993

. ffrè Editore, 1962

VILLEGAS H. Curso de Direito Tributário. São Paulo, Revista dos Tribunais, 1980.

e Agentes de Percepção. In: Revista de Direito Tributário, v. 6. São Paulo, R.T., 1986. 